\title{
Missing links: Safeguarding and disability hate crime responses
}

\begin{tabular}{|r|l|}
\hline Journal: & The Journal of Adult Protection \\
\hline Manuscript ID & JAP-09-2021-0030.R3 \\
\hline Manuscript Type: & Research Paper \\
\hline Keywords: & $\begin{array}{l}\text { Safeguarding, disability, hate crime, making safeguarding personal, Care } \\
\text { Act, criminal justice }\end{array}$ \\
\hline
\end{tabular}

\section{SCHOLARONE" \\ Manuscripts}




\title{
Missing links: Safeguarding and disability hate crime responses
}

\author{
Abstract \\ Purpose
}

This paper considers the relationship between disability hate crime and safeguarding adults. It critically considers whether safeguarding responses to disability hate crime have changed following the implementation of the Care Act 2014. Historically, protectionist responses to disabled people may have masked the scale of hate crime and prevented them from seeking legal recourse through the criminal justice system. This paper investigates whether agencies are working together effectively to tackle hate crime.

Design / methodology

The research presented draws on semi-structured interviews with key informants who work with disabled people and organisations, as part of a wider study on disability hate crime.

Findings

Prior to the Care Act safeguarding practice often failed to prioritise criminal justice interventions when responding to reports of disability hate crimes. Improving engagement within multi-agency safeguarding hubs (MASH) and Boards has the potential to increase hate crime awareness and reporting.

Research limitations

The research was limited in scope to 15 participants who worked in England within safeguarding teams or with victims of hate crime.

Practical implications

Raising the profile of disability hate crime within safeguarding teams could lead to achieving more effective outcomes for adults at risk: improving confidence in reporting, identifying perpetrators of hate crimes, enabling the criminal justice system to intervene and reducing the risk of further targeted abuse on the victim or wider community.

Originality / Value

This paper is original in its contribution in this field as there is a dearth of research on the relationship between safeguarding and disability hate crime. 
Key words: safeguarding, disability, hate crime, making safeguarding personal, Care Act

Paper type: Research paper

\section{Introduction}

This paper considers the relationship between disability hate crime and safeguarding adults' practice in England. It argues how historical, well intentioned, but protectionist responses from safeguarding practitioners may have masked the scale of hate crime in the UK and prevented disabled people from seeking legal recourse through the criminal justice system (CJS). Utilising research undertaken by the first author, the paper identified how, prior to the Care Act 2014, there was limited awareness of disability hate crime and a gap in understanding and response by key agencies. This evidence is considered in light of the introduction of the Care Act. There are clear links to adult safeguarding practice and opportunities to improve outcomes for disabled adults through raising awareness of the status of hate crime, beyond reducing the risk to an individual. At a time when changes to the strategic and operational practice in safeguarding adults continue to be embedded through the Act, this paper raises important questions for practice.

Police recorded disability hate crimes in England and Wales increased by $9 \%$ in 2020-21 to 9,943 cases, the highest on record (Home Office, 2021). However, as many as 50,000 disability hate crimes occur yearly through self-report victim surveys (Home Office, 2018), suggesting significant underreporting by victims (Richardson et al., 2016). Furthermore, where hate crimes are reported, incidents are not explicitly recorded as such, closing off possible recourse through the CJS (Healy, 2020). Although a link to safeguarding issues and criminality is evidenced in the Care Act Statutory Guidance, under the more general terminology of 'criminal offences' (DHSC, 2021), there is no explicit reference to hate crime. The Care Act provides a statutory footing for safeguarding adults, which strengthens joint responsibilities of agencies in implementing appropriate safeguarding responses, however research highlights a continued gap in response to disability hate crimes (Hafford-Letchfield et al., 2020).

This paper considers whether there are barriers to criminal justice, health and social care practitioners' recognition of and response to disability hate crimes through safeguarding teams. The next section considers disability hate crime and multi-agency responses to it. The paper then presents the methodology, followed by thematic analysis of the findings, including failures to identify disability hate crimes, and a dearth of information sharing between safeguarding teams. Finally, it interrogates these findings in light of the Care Act and investigates whether agencies 
working within this new legislative and practice context have greater opportunity to address hate crimes against disabled people.

\section{What is a disability hate crime}

In the UK, disability is one of nine protected characteristics enacted by the Equality Act 2010 and one of five legally protected characteristics under hate crime legislation. A disability hate crime is a criminal offence which is perceived by the victim or any other person to be motivated by hostility or prejudice based on a person's disability or perceived disability (College of Policing, 2020). This includes physical, mental, emotional or sexual violence, abuse or assault, and targeting of individuals or of property. A person is regarded as having a disability if they have a physical or mental impairment that has a substantial and long-term adverse effect on that person's ability to carry out typical day-to-day activities. The United Nations Convention on the Rights of Disabled People (2006) (CRDP) recognises disability as impairments in interaction with societal barriers, acknowledging the role of negative attitudes, 'unwelcoming' and disabling environments, in line with the Social Model of disability (Shakespeare 2006; Sherry, 2013; Thomas, 2004).

Disability hate crimes can include both hate crimes (criminal acts) and hate incidents (where behaviour, however unpleasant, is not in breach of existing criminal law). As such, only hate crimes can be prosecuted, but even then prosecution is limited in scope, in accordance with the Criminal Justice Act 2003 s146. Presently, the only method available for prosecuting disability hate crimes is to increase the sentencing where it has been proven that an offence was motivated by, or demonstrative of, disability hostility (though the Law Commission are currently reviewing hate crime legislation, 2020). This places an onus on the CJS to prove an offence was motivated by hostility or prejudice, reflected in low prosecution figures for disability hate crimes (Home Office, 2021). As such, this paper proposes that safeguarding processes provide an avenue for improving recorded figures.

\section{Perceptions of 'vulnerability' and changes in adult safeguarding practice under the Care Act 2014}

Increasingly, evidence highlights poor recognition of hate crimes within communities, organisations and strategic groups (Hafford-Letchfield et al, 2020; Roulstone and Sadique, 2013; Sin et al., 2009; Walters and Brown, 2016). Consequently, a lack of recognition leads to under-reporting and denies many disabled people the right to seek criminal justice recourse if a crime has been committed against them. Constructions of disabled people as vulnerable can further result in a focus on neutralising or minimising risk to adults, which can overshadow any desire to pursue criminal investigation (Pritchard-Jones, 2018). This focus on a 'vulnerable victim' resultingly reinforces the 
assumption that disabled people are dependent and in need of 'protection' (Ralph et al., 2016; Roulstone and Sadique, 2013; Sin, 2014). Roulstone et al. (2011) suggest that perceived vulnerability also places blame on the victim, encouraged by safeguarding approaches which concentrate on reduction of risk to the individual, particularly for those with learning disabilities. Safeguarding and criminal justice responses are thus contributing to and perpetuating constructions of disabled people as vulnerable (Brookes, 2013).

A positive outcome of the Care Act was the change in language around safeguarding, replacing the term 'vulnerable adult' with 'adult at risk.' Within the Act, the term 'adult at risk' refers to adults who are experiencing, or are at risk of, abuse or neglect and are unable to protect themselves because of their need for care and support (s42). This presents a welcome shift in emphasis as the label 'vulnerable adult' faced criticism as having the potential to be a "self-fulfilling prophecy" (Stevens, 2013, p. 87). Additionally, the Act places duties on Local Authorities to provide advice and support to people who may be at risk of, or experiencing, abuse or neglect if they do not meet the threshold for enquiry under s42. This suggests a move to introduce conversations about prevention as well as incident-led responses; presenting opportunities to promote awareness around hate crimes.

For people who may be 'adults at risk' this shift of ethos in the Act presents an opportunity to actively engage in conversations about desired outcomes, and promote informed choice about options for the individual. The Act further establishes a fundamental focus on a person-centred approach to safeguarding through 'Making Safeguarding Personal' (MSP); adopting key principles of partnership, protection, empowerment, proportionality and prevention. MSP as an approach to working with adults at risk addresses the disjuncture between procedural compliance and achieving better outcomes for adults with care and support needs. The MSP ethos, adopted into the language of the Act, is clear about the intention to place people as experts of their own lives, as well as balancing the need for safety and protection, with that of wellbeing.

\section{Multi-agency engagement and response}

Evidence suggests there is limited recognition of disability hate crime through safeguarding practices. Farquharson (2016) reviewed safeguarding referrals made by 152 local authorities in England and compared these with the referrals received by police, where they were tagged with a 'vulnerable adult' flag on the police computer system. She found that $87 \%$ of all referrals for alleged abuse did not establish that a crime had been committed (750 referrals) and only $1 \%$ resulted in court proceedings or a caution. Of the local authority referrals, 368 single agency referrals found no police involvement was required, as the Police were never informed of potential criminality. 
Farquharson found only four cases where a perpetrator was convicted, suggesting there may be potentially missed opportunities for police involvement. In a smaller scale study, Fyson and Kitson (2012) identified 15 out of a potential 42 safeguarding referrals which had resulted in a 'substantiated' outcome, whereby an investigation concluded abuse had occurred. Police were involved in only eight of those 42 cases and attended a safeguarding multi-agency meeting in just three. Farquarson (2016) suggests there continue to be barriers to social care managers routinely referring to the Police. Agencies reported frustration at the disruption caused by what they describe as ongoing and lengthy police investigations (Fyson \& Kitson, 2012; Rees and Manthorpe, 2010), which may have been a factor in decision-making.

Additionally, disparity exists in terms of the point at which local authorities will intervene, as evidenced by Montgomery et al. (2016) in their review of adult care. Initial results from a review of post-Care Act safeguarding suggests there was an increase in referrals since the Act was implemented, and potentially better outcomes for service users and social care staff as a result (Butler and Manthorpe, 2016; Cooper and Bruin, 2017). This may be a consequence of increased strategic ownership of local practices through Safeguarding Adults Boards, which Cooper and Bruin (2017) suggest encourages greater accountability. Notwithstanding, there are differences in the way local arrangements work, such as team configurations, and how field teams manage safeguarding responses. This study explored the interface between different agencies and how they can best support victims of disability hate crime.

\section{Methodology}

This research is drawn from a completed $\mathrm{PhD}$ examining disabled people's experiences of hate crime conducted by the first author (Healy, 2020). This paper presents findings from key informant interviews with 15 individuals working in criminal justice agencies (police and CPS), victim support, third party reporting organisations, a housing association, a local authority, disabled people's userled organisations and a disability campaigner. They were interviewed prior to the introduction of the Care Act (one in 2013 and the remainder in 2014) and worked across a range of service providers in England including within safeguarding teams. Recruitment was via email introductions to identified individuals working in the field of disability hate crimes and snowballing via informants. Their views were analysed on a variety of disability hate-related issues, including the challenges of inter- and multi-agency working, examples of good practice and recommendations for improvements. The research findings are limited in terms of those individuals who participated in the study, and the time at which the interviews took place. Findings are thus reflected upon in light of the introduction of the Care Act. 
Interviews were semi-structured and thematically analysed with the aid of an NVivo software package (Bryman, 2016; QSR NVivo 8.0 and 10.0). The data analysis followed the principles of 'open coding' within a constructivist perspective, and data was developed into key themes (Bryman, 2016). Participation in the interviews was confidential and data was anonymised. The research received ethical approval from Middlesex University's Ethics Sub-Committee.

\section{Findings}

The role of safeguarding in disability hate crime identification

Social service agencies have a duty to respond to safeguarding concerns in accordance with the Care Act, which includes subtler forms of harm such as emotional or psychological abuse or neglect (Rees \& Manthorpe, 2010). Disabled people may report their experiences of victimisation to social and health services such as GPs, therapists, care workers, housing and social services staff (Healy, 2018), all of whom have the potential to identify these concerns as a safeguarding issue. In the interviews, the participants emphasised that inter-agency collaboration was a priority and safeguarding policies must be followed when dealing with clients and complainants. For example, Max (who worked for the Crown Prosecution Service[i]) acknowledged there is a need for criminal justice agencies to engage with safeguarding teams better, to raise the profile of disability hate crimes and ensure any potential gap in knowledge is addressed. However, the complexity of some hate crime cases can at times mean engaging safeguarding measures for both victim and perpetrator. As Leah (Police lead for Hate Crime) points out, often:

you are dealing with a vulnerable person as the offender and a vulnerable person as the victim [and] there are safeguarding issues across the board.

Thus, the role of adult safeguarding can be challenging in terms of identifying and meeting the needs of both victim and alleged perpetrator. However, safeguarding referrals are a first point of contact with CJS, health, and social services and present an opportunity to consider hate crime in the context of the reported concern. The interviews demonstrated how responses to potential hate crime were, in many cases, protectionist at best. This protectionism, however well intentioned, potentially contributed to under reporting of disability hate crime and a wider cultural acceptance of such behaviour in communities.

Since the interviews, the Care Act outlines a duty to make enquiries into these types of concerns, however there is an implicit focus on the adult at risk over and above any consideration of action regarding an alleged perpetrator. Whilst discriminatory abuse is now set out as a category of harm in the Care Act Statutory Guidance, and in operational safeguarding procedures, this paper proposes 
that consideration of any harm as potentially a criminal act is not necessarily explicit. It is unclear whether practice has changed with the implementation of new legislation for adult safeguarding and remains an area for research and inquiry.

The participants highlighted the challenges that can be faced around enacting cultural and procedural change in relation to the perception of, and response to, hate crime in adult safeguarding. Riley (Learning Disability Coordinator) believes local authority's protectionist responses are inherent in the concept of safeguarding because they focus "on the victim which means that the perpetrator justice is gone". He has worked for over 30 years with learning disability services and has direct and regular engagement with safeguarding adults' teams, and argues that safeguarding services are not fit for purpose, suggesting that only a very small percentage of safeguarding referrals resulted in criminal justice-related interventions.

This may be a consequence of what Montgomery and colleagues (2017, p. 154) describe as the "minimalist or least interventionist approach" to reports of targeted violence and abuse. In cases where evidence is available, Riley states that a typical safeguarding response is to remove the victim from further risk of harm:

we've got lots of examples where finally people have spoken up about hate crime for example and say you know I was on the bus and this is what happened to me on the bus and the response from the social care staff is, well use a different bus then (Riley).

Amy (a disabled activist) recounted a similar case where a hate crime victim was moved from their home following a safeguarding meeting, demonstrating how a focus on reducing the risks of further harm potentially benefited the victim, but did not include pursuing recourse to the criminal behaviour at the root.

Evidence suggests care workers and family members similarly 'minimalise' or normalise the effect of these experiences, in an attempt to reduce the impact of it (cf. Sin et al., 2009). George (Victim Support Manager) supports this in saying:

very often they have to use an intermediate to report i.e. a carer and the carer's attitude is oh well, these things happen, you know, live with it, that sort of thing (George).

This minimalisation of seriousness contributes to a lack of recognition of disability hate crime, and thus more training is needed of care and community support workers to recognise and report the signs of abuse so they can be addressed at multi-agency or criminal justice levels. 
At the time of interviews, challenges to effective information sharing across agencies were evident in the literature (Brown, 2004; Stevens, 2013). Similarly, this research identified that in cases where safeguarding enquiries were instigated, problems arose with regards to who was responsible for dealing with reports. Both Riley and Susie (a support worker with 20 years' experience with disabled groups) described how referrals were passed between organisations within safeguarding teams, with no clear action taken by any one individual. Riley describes it as a situation where: "nobody's putting the bigger picture together."

Additionally, according to both Riley and Susie, the term 'hate crime' was not familiar to many agencies with many cases not recognised as hate crimes, something Susie says she has raised "time and again over the years". She describes a case where a learning disabled woman's support worker did not know how to raise a safeguarding concern. Despite evidence of disability hate crime, she said:

[the] person on the triage team on the safeguarding team I spoke to could not understand how this was a crime, she couldn't understand how it was a disablist hate crime, she didn't know the term hate crime (Susie).

Both participants reported that this is a particular problem for learning disabled communities though is evidenced across other forms of disability and impairment.

Additionally, there are missed opportunities in engaging with organisations beyond criminal justice agencies. Housing organisations can at times fail to be embedded in partnership working and have been identified as 'weak' in their responsibilities to adult safeguarding (Cass 2015; Hunter et al., 2007; Parry, 2013). Interview participant and housing officer Emily, who had been in post for four years, recounted numerous cases where disabled victims were dealt with by an internal housing support team to resolve their complaints, but said unless the police were directly involved by referring reports to them, this information was not addressed elsewhere. Parry $(2013$, p. 16) suggested there is "widespread ignorance" about the role of housing in adult safeguarding and the extent of involvement varies by local authority, yet MacDonald et al. (2017) found that $26 \%$ of reported disability hate incidents went to housing services. This demonstrates missed opportunities by housing departments and associations, in dealing with disputes, to recognise and report safeguarding cases and thus create accurate and valuable links into police referrals.

\section{Discussion}

Ongoing challenges to effective information sharing across agencies emerged as a strong theme, and resonates with other publications (Brown, 2004; Stevens, 2013). Where safeguarding practices have 
been followed, there is the opportunity for speedy resolution in high risk situations, by multi-agency engagement, as evidenced by Rees and Manthorpe (2010). This study's participants identified that coordination and cooperation between agencies is a crucial factor. Unfortunately, intervention can often mean a sole focus on reducing the risk to the victim, without recourse for the perpetrator. Multi-agency safeguarding hubs (MASH) provide an opportunity to bring together CJS and local authority safeguarding teams in identifying, reporting and resolving disability hate crimes. An evaluation of their efficacy and impact following the embedding of the Care Act in practice is required however. George, Riley and Susie identified intrinsic problems with putting safeguarding processes into practice, and so this paper proposes further research into whether the Care Act has embedded safeguarding practices in full, and whether the Act has improved operational responses to harm and crime. Safeguarding hubs have the potential to identify and engage with high risk situations and potentially vulnerable victims who might not otherwise identify their experiences as hate crimes or who might not see the point of reporting incidents. Fundamentally, multi-agency working needs to be strengthened, and recognise hate crime as a criminal offence by acknowledging the intentionality of the act.

Awareness of hate crime as a dimension of safeguarding practice and the potential ways of addressing it therefore requires education across agencies. Shah (2015) encourages adult care organisations to better recognise the relationships between characteristics of 'harm' and disability hate crime, as both include, for example, harassment, abuse, bullying, neglect and violence. If a person's disability is a factor in violence against them then this must be considered both a safeguarding concern and a potential disability hate crime. As such, any suspicions should trigger alerts not just for safeguarding but also suspected hate crime.

To facilitate an individual making informed choices requires knowledge of options available to them, and support to enact those options. Awareness of hate crime and how it can present in practice is therefore vital for practitioners and adults at risk, as well as commitment to partnership working, including all relevant agencies. There are multiple ways in which hate crime can impact individuals (Ralph et al., 2016), and it must be acknowledged that for many disabled adults they will play an active role in their own protection (Hollomotz, 2012). Additionally, as mentioned by Leah above, the relationship between victim and perpetrator may involve the provision of care or support for both, and so the complexities of relationships and need can influence the victim's view of the situation. Care must be taken in the context of complex cases where there exists both vulnerable victim and perpetrator (Sin, 2015; Walters and Hoyle, 2012). Moreover, dimensions of harm may be poorly understood or acknowledged by professional responding to them, many of which can be understood 
as hate crimes, including verbal, physical, sexual, financial and psychological abuse. This suggests practitioners need to appreciate both emotional and practical implications for individuals to ensure their wellbeing and safety are addressed.

\section{Conclusion and practice recommendations}

Approaches to disability hate crime continue to face challenges in terms of awareness, inter-agency working, interpretations of vulnerability and failures to protect disabled people (EHRC, 2012; MasonBish, 2013; Quarmby, 2011). A balance of justice and protection is needed within safeguarding responses to underpin links between disability hate crime, safeguarding duties and prosecutable offences. Effective multi-agency working in safeguarding hubs and Boards, and access to advocacy to support informed choices about options, has the potential for both individual impact (increased reporting) and to prevent repeat victimisation through community awareness and intervention. Interventions must be adequate and swift and must ensure assumptions are not being made about the 'vulnerability' of victims (Sin, 2016). Where risks are identified, the response should not be restricted to protecting or removing the victim only, but also to police referral.

Prior to the Care Act it appears from the evidence that a local authority's primary objective was safeguarding the at-risk individual, over and above addressing perpetrator behaviour. Agency response should attempt to balance the need to protect people with empowering them to make their own choices and decisions (Stevens, 2013). This requires open and collaborative conversations about managing risk between agencies and the adults concerned.

Strategic aims of shifting to a partnership and empowerment focus where the person and the outcomes they want to achieve are prioritised, are becoming embedded more firmly into practice through Making Safeguarding Personal (Briggs and Cooper, 2018). Academics and practitioners recognise changes introduced by the Act require significant cultural and procedural adaptions in both strategic and operational process across agencies (Butler and Manthorpe, 2016; Cooper and Bruin, 2017). Further research is needed therefore to consider how these changes are experienced in practice, and what difference it makes to approaches on an operational level, as well as service user outcomes. Consideration must be given to how different communities are vulnerable to hate crimes in different ways, resulting in ongoing challenges for local agencies in responding to the needs of their diverse communities (Wong and Christmann, 2017). Safeguarding adult boards and 
hubs have the potential to raise the profile and thus enhance the service provision for all forms of hate crime, but only with collective recognition and action.

This paper acknowledges social workers and safeguarding teams may continue to face ongoing challenges between the need to safeguard potential victims from abuse and the same time support individual's rights to independence, choice and social inclusion (Fyson and Kitson, 2010). Although the need for multi-agency working is evidenced, its implementation has historically been challenging (Sin, 2016). Agencies may not necessarily recognise they have a role to play in preventing or addressing hate crime, as existing literature indicates a lack of effective multi-agency response or coordination in many cases (Brown and Stein, 2000; Hafford-Letchfield et al., 2020; Quarmby, 2011; Richardson et al., 2016; Sin, 2016). Many professional partners in health and social care organisations, as well as housing and education, are slow to acknowledge their role, or to respond to it (Sin et al., 2009). There are some signs of success, such as localised projects that have collaborated across agencies to raise awareness and implement support systems (Sin, 2014) which, although encouraging, underline the need for greater coordination and implementation of interventions nationally. Accordingly, there have been calls for a national analysis of safeguarding processes to establish a more comprehensive understanding of protocols and processes (Doherty, 2015).

It is acknowledged by the authors that this study sample represents a small cross-section of practitioners, however wider themes from extant literature suggest awareness of the legislation on hate crime was not embedded in practice prior to the Care Act. This raises questions as to whether there will continue to be missed opportunities within current practice to strengthen responses against people who perpetrate abuse, and more specifically hate crimes, towards disabled people. MASH now provide leadership and potentially more robust coordination of information around hate crimes, but commitment and collaboration are required from agencies across health and social care, as well as criminal justice, to better understand, respond to and prevent hate crimes. Without such recognition there are long term consequences for targeted individuals, communities and society. There must be a willingness to challenge any acceptance or minimalisation of hate crime.

To work towards fully embedding changes in safeguarding adult practice through the Care Act requires consistent leadership from Safeguarding Adult Boards to influence culture change in practice and communities. Further research on disability hate crimes in a post Care Act context is needed to investigate whether changes are embedding into practice and ideally demonstrate a shift from the findings presented herein. 
This paper proposes areas where the link needs to be made more explicit between discriminatory abuse and disability hate crime, from both an operational and strategic perspective. This encompasses professionals of all disciplines and agencies, so the links between supporting adults at risk and addressing perpetrator behaviour do not operate in isolation. Raising the profile of disability hate crime within safeguarding adults hubs and boards could lead to improved outcomes for adults at risk but this is not a task for social care alone. Identifying disability hate crime as a criminal offence demands a focus wider than simply reducing the risks to the adult but will improve confidence in reporting hate crimes. It identifies perpetrators of hate crimes, enabling the CJS to intervene and thus reduces the risk of further targeted violence or abuse on the victim or wider community. Recognising and responding to hate crimes as such promotes a culture of zero tolerance, creating more cohesive, accepting and safer communities.

\section{References}

All Party Parliamentary Group on Hate Crime (APPG)(2019), "How Do We Build Community Cohesion When Hate Crime Is On The Rise?", APPG on Hate Crime, London.

Briggs, M. and Cooper, A. (2018), "Making Safeguarding Personal: progress of English local authorities", The Journal of Adult Protection, Vol. 20 No. 1, pp. 59-68.

Brookes, S. (2013), "A case for engagement: the role of the UK Disability Hate Crime Network (DHCN)", Roulstone, A. and Mason-Bish, H. (Eds), Disability, Hate Crime and Violence, Routledge, London, pp. 126-134.

Brown, H. (2004), "A Rights-Based Approach to Abuse of Women with Learning Disabilities", Tizard Learning Disability Review, Vol. 9 No. 4, pp. 41-44.

Brown, H. \& Stein, J. (2000), "Monitoring adult protection referrals in 10 English local authorities", The Journal of Adult Protection, Vol. 2 No. 3, pp. 19-31.

Bryman, A. (2016), Social Research Methods, OUP, Oxford.

Butler, L. \& Manthorpe, J. (2016), "Putting people at the centre: facilitating Making Safeguarding Personal approaches in the context of the Care Act 2014", The Journal of Adult Protection, Vol. 18 No. 4, pp. 204-213.

Care Act 2014, available at: https://www.legislation.gov.uk/ukpga/2014/23/contents/enacted (accessed 15 July 2021).

Cass, E. (2015), "The role of housing in adult safeguarding", Housing, Care \& Support, Vol. 18 No. 2, pp. 51-55. 
College of Policing (2020) "Hate Crime", available at: https://www.app.college.police.uk/appcontent/major-investigation-and-public-protection/hate-crime/

Cooper, A. \& Bruin, C. (2017), "Adult safeguarding and the Care Act (2014) - the impacts on partnerships and practice", The Journal of Adult Protection, Vol. 19 No. 4, pp. 209-219.

Criminal Justice Act 2003. Available at: https://www.legislation.gov.uk/ukpga/2003/44/contents (accessed 15 July 2021).

Department of Health and Social Care (DHSC) (2021), "Care Act Statutory Guidance", available at: https://www.gov.uk/government/publications/care-act-statutory-guidance/care-and-supportstatutory-guidance (accessed 1 June 2021).

Doherty, G. (2015), "Do mates hate? A framing of the theoretical position of mate crime and an assessment of its practical impact", The Journal of Adult Protection, Vol. 17 No. 5, pp. 296-307.

Equality Act 2010, available at: https://www.legislation.gov.uk/ukpga/2010/15/contents (accessed 15 July 2021).

Equalities and Human Rights Commission (2012), "Out in the Open: Tackling disability-related harassment: A manifesto for change", EHRC, London.

Farquharson, J. A. (2016), "Referrals to the police of vulnerable adult abuse", The Journal of Adult Protection, Vol. 18 No. 2, pp. 119-127.

Fyson, R. \& Kitson, D. (2012,) "Outcomes following adult safeguarding alerts: a critical analysis of key factors", The Journal of Adult Protection, Vol. 14 No. 2, pp. 93-103.

Hafford-Letchfield, T., Carr, S., Faulkner, A., Gould, D., Khisa, C., Cohen, R. and Megele, C., (2020), "Practitioner perspectives on service users experiences of targeted violence and hostility in mental health and adult safeguarding", Disability \& Society, pp. 1-26.

Healy, J. C. (2018), "On the periphery of hate crime: Disability at the intersections of marginalisation, vulnerability, and difference", Thesis (PhD), Middlesex University, London, available from: http://eprints.mdx.ac.uk/25907/.

Healy, J. C. (2020), "It spreads like a creeping disease': Experiences of victims of disability hate crimes in austerity Britain", Disability \& Society, Vol. 35 No. 2, pp. 176-200.

Hollomotz, A. (2012), "A lad tried to get hold of my boobs so I kicked him: an examination of attempts by adults with learning difficulties to initiate their own safeguarding", Disability \& Society, Vol 27 No. 1, pp. 117-129.

Home Office (2018), "Hate Crime, England and Wales 2017/18”, available at: https://www.gov.uk/government/statistics/hate-crime-england-and-wales-2017-to-2018

Home Office (2021), "Hate Crime, England and Wales, 2020/2021. Statistical Bulletin 26/21", available at https://www.gov.uk/government/statistics/hate-crime-england-and-wales-2020-to2021/hate-crime-england-and-wales-2020-to-2021 
Hunter, C., Hodge, N.S., Nixon, J., Parr, S. \& Willis, B. (2007), “Disabled people's experiences of antisocial behavior and harassment in social housing: a critical review. Project Report", Disability Rights Commission, London.

Law Commission (2020), "Hate crime laws: a consultation paper. Consultation Paper 250", Crown Copyright, London.

Macdonald, S., Donovan, C. \& Clayton, J. (2017), "The disability bias: understanding the context of hate in comparison with other minority populations", Disability and Society, Vol. 12 No. 4, pp. 483499.

Mason-Bish, H. (2013), "Conceptual issues in the construction of disability hate crime", in Roulstone, A. \& Mason-Bish, H. (Ed.s), Disability, Hate Crime and Violence, Routledge, London, pp. 11-24.

Montgomery, L., Anand, J., Mackay, K., Taylor, B., Pearson, K.C. \& Harper, C.M. (2016), “Towards explanations for the findings of serious case reviews: understanding what happens in self-neglect work", The Journal of Adult Protection, Vol. 18 No. 3, pp. 131-148.

Parry, I. (2013), "Adult safeguarding and the role of housing", The Journal of Adult Protection, Vol. 15 No. 1 , pp. 15-25.

Pritchard-Jones, L. (2018), “"Adults at risk": "vulnerability" by any other name?", The Journal of Adult Protection, Vol. 20 No. 1, pp. 47-58.

Quarmby K. (2011) Scapegoat: How we are failing disabled people, Portobello Press, London.

Ralph, S., Capewell, C. and Bonnett, E. (2016), "Disability hate crime: persecuted for difference", British Journal of Special Education, Vol. 43 No. 3, pp. 215-232.

Rees, P. \& Manthorpe, J. (2010), "Managers' and Staff Experiences of Adult Protection Allegations in Mental Health and Learning Disability Residential Services: a Qualitative Study", British Journal of Social Work, Vol. 40, pp. 513-529.

Richardson, K., Beadle-Brown, J., Bradshaw, J., Guest, C. Malovic, A. \& Himmerich, J. (2016), "“I felt that I deserved it" - experiences and implications of disability hate crime", Tizard Learning Disability Review, Vol. 21 No. 2, pp. 80-88.

Roulstone, A. and Sadique, K. (2013), "Vulnerable to misinterpretation: disabled people, 'vulnerability', hate crime and the fight for legal recognition", in Roulstone, A. \& Mason-Bish, H. (Ed.s), Disability, Hate Crime and Violence, Routledge, London, pp. 25-39.

Roulstone, A., Thomas, P. \& Balterston, S. (2011), "Between hate and vulnerability: unpacking the British criminal justice system's construction of disablist hate crime", Disability \& Society, Vol. 26 No. 3, pp. 351-364.

Shah, R. (2015), "Disability Hate Crime is Everyone's Business", in Shah, R. \& Giannasi, P. (Ed.s), Tackling Disability Discrimination and Disability Hate Crime, Jessica Kingsley, London, pp. 123-138.

Shakespeare, T. (2006), Disability Rights and Wrongs, Routledge, Oxon. 
Sherry, M. (2013), "International perspectives on disability hate crime", in Roulstone, A. \& MasonBish, H. (Ed.s), Disability, Hate Crime and Violence, Routledge, London pp. 80-91.

Sin, C. H. (2013), "Making disablist hate crime visible: Addressing the challenges of improving reporting", in Roulstone, A. \& Mason-Bish, H. (Ed.s), Disability, Hate Crime and Violence, Routledge, London, pp. 147-165.

Sin, C. H. (2014), "Using a 'layers of influence' model to understand the interaction of research, policy and practice in relation to disablist hate crime", in Chakraborti, N. \& Garland, J. (Ed.s), Responding to hate crime: the case for connecting policy and research, Policy Press, Bristol, pp. 99112.

Sin, C. H. (2015), "Hate crime against people with disabilities", in Hall, N., Corb, A., Giannasi, P. \& Grieve, J.G.D. (Ed.s) The Routledge International Handbook on Hate Crime, Oxon, Routledge, pp. 193206.

Sin, C.H. (2016), "Commentary on 'I felt I deserved it' - experiences and implications of disability hate crime", Tizard Learning Disability Review, Vol. 21 No. 2, pp. 89-94.

Sin, C. H., Mguni, N., Cook, C., Comber, N. \& Hedges, A. (2009), "Disabled victims of targeted violence, harassment and abuse: barriers to reporting and seeking redress", Safer Communities, Vol. 8 No. 4 , pp. 27-34.

Stevens, E (2013), "Safeguarding vulnerable adults: exploring the challenges to best practice across multi-agency settings", The Journal of Adult Protection, Vol. 15 No. 2, pp. 85-95.

Thomas, C. (2004), "How is disability understood? An examination of sociological approaches", Disability \& Society, Vol. 19 No. 6, pp. 569-583.

United Nations (2006), "Convention on the Rights of Persons with Disabilities (CRPD)", GA Resolution 61/106, December 132006.

Walters, M. \& Brown, R. (2016), “Preventing Hate Crime: Emerging practices and recommendations for the improved management of criminal justice interventions" Sussex Crime Research Centre \& INHS.

Walters, M. \& Hoyle, C. (2012), "Exploring the everyday world of hate victimization through community mediation", International Review of Victimology, Vol 18 No. 1, pp. 7-24.

Wong, K. and Christmann, K. (2016), "Increasing Hate Crime Reporting: Narrowing the Gap between Policy Aspiration, Victim Inclination and Agency Capability", British Journal of Community Justice, Vol. 14 No. 3, pp. 5-23. 
['] Participants names have been changed. 